\author{
Asian Journal of \\ Medical and Biological Research \\ ISSN 2411-4472 (Print) 2412-5571 (Online) \\ www.ebupress.com/journal/ajmbr
}

\title{
Short Communication \\ A case study on needling technique as a treatment for ocular setariasis in eye of a horse
}

Mizanur Rahman ${ }^{1}$, Eaftekhar Ahmed Rana ${ }^{2}$, Mohaiminul Islam Tanvir ${ }^{3}$, Abdullah Al Momen Sabuj ${ }^{4}$, Mohammed Ashif Imtiaz ${ }^{5}$ and Tanjila Hasan ${ }^{6 *}$

${ }^{1}$ MS student, Department of Medicine and Surgery, Faculty of Veterinary Medicine, Chittagong Veterinary and Animal Sciences University, Khulshi, Chittagong-4225, Bangladesh

${ }^{2}$ MS student, Department of Microbiology and Veterinary Public Health, Chittagong Veterinary and Animal Sciences University, Khulshi, Chittagong-4225, Bangladesh

${ }^{3}$ MS Student, Department of Genetics and Animal Breeding, Chittagong Veterinary and Animal Sciences University, Chittagong-4225, Bangladesh

${ }^{4}$ MS Student, Department of Microbiology and Hygiene, Bangladesh Agricultural University, Mymensingh2202, Bangladesh

${ }^{5}$ Department of Physiology, Biochemistry and Pharmacology, Chittagong Veterinary and Animal Sciences University, Khulshi, Chittagong-4225, Bangladesh

${ }^{6}$ Department of Medicine and Surgery, Chittagong Veterinary and Animal Sciences University, Khulshi, Chittagong-4225, Bangladesh

*Corresponding author: Tanjila Hasan, Department of Medicine and Surgery, Faculty of Veterinary Medicine, Chittagong Veterinary \& Animal Sciences University, Khulshi, Chittagong-4225, Bangladesh.

Phone: +8801735509192; Fax: +880-031-659620; E-mail: tanjila.cvasu@ gmail.com

Received: 07 September 2017/Accepted: 20 September 2017/ Published: 28 September 2017

\begin{abstract}
A 2.5 year old male horse was presented to Teaching Veterinary Hospital, VCRI, Namakkal, India with the history of lacrimation, impaired vision and progressive corneal opacity in left eye. Clinical examination revealed movement of a thread like worm in the anterior chamber of the eye. For removal of the worm, affected eye was prepared for surgery by deep sedation with xylazine hydrochloride. Then general anaesthesia was done with Ketamine hydrochloride and maintained by isoflurane. After induction, worm was removed by needling technique. Topical antibiotic and steroid were administered postoperatively to check secondary bacterial infection and corneal opacity. After surgery, the vision was restored and corneal opacity was reduced gradually. Morphologically, the worm was identified as Setaria spp. This is a common case in India due to vector prevalence.
\end{abstract}

Keywords: needling technique; Setaria spp; eye; horse

\section{Introduction}

Ocular setariasis is a disease of equine resulting from ectopic parasitisim caused by Setaria spp. under the genus Setaria (Gangwar et al., 2008). Generally, the parasite can be found in various organs such as heart, lung, spleen, kidney, uterus, oviduct, ovary and urinary bladder, as well as in the contents of rumen, reticulum and abomasum (Mandal et al., 1994). The parasite is transmitted by mosquitoes through the blood stream (Varma $e t$ al., 1971). In Indian subcontinent, it occurs mostly in summer and autumn seasons when the vectors (Anopheles peditaneniatus and Culex nilgiricus) are most prevalent (Mritunjay et al., 2011).

The parasite exhibits migratory behavior in unnatural hosts such as horses, donkeys or human beings and immature worm can invade eye (Sreedevi et al., 2002; Tuntivanich et al., 2011) through the vascular system (Townsend, 2013). The erratic movement of the worm within the anterior chamber of the eye may cause severe 
irritation to the cornea causing corneal opacity. Infected animals usually manifesting signs of lacrimation, photophobia, conjunctivitis (Gangwar et al., 2008) and impaired vision, in cases when treatment is delayed (Basak et al., 2007). Though, involvement of the eye is commonly unilateral but bilateral occurrence was reported too (Shin et al., 2002; Buchoo et al., 2005).

The main goal of treatment is to exterminate the parasite either by medical or surgical approaches. Treatment with ivermectin is likely to be promising (Mohammad et al., 2007). However, using this approach, a minimum of 15 days may elapse from the time of the ivermectin injection until the parasite dies, which can result in a delayed resorption of dead parasite in the anterior chamber causing persistent ocular inflammation. The best treatment of ocular setariasis is the surgical removal of the parasite (Tuntivanich et al., 2011) that can be performed under general anaesthesia or regional nerve blocks. Surgical interventions used for treatment of ocular setariasis include needling technique at 3 O' clock (Sreedevi et al., 2002) and nick incision at 12 O' clock position of the limbus of eye (Buchoo et al., 2005). Between two surgical approaches needling technique is a simple and quick method and the post-operative complications are also minimum (Singh et al., 1976).

The objective of the present study is to describe a detailed surgical procedure of needling technique for removing Setaria spp. from anterior chamber of affected eye of a horse and to observe the recovery of corneal opacity.

\section{Case History}

A 2.5 year- old male horse was brought to the Teaching Veterinary Hospital, VCRI, Namakkal, India with a complaint of a parasite had been noticed by the owner in the anterior chamber of the horse's left eye for 7 days. The cornea initially appeared clear and then quickly became cloudy. Topical chloramphenicol ointment had been administered twice daily, but corneal opacity continued to progress. The owner also reported that no anthelmentic was administered to the horse.

\section{Clinical and Laboratory Findings}

The clinical examination revealed lacrimation, corneal opacity, conjunctivitis and impaired vision in the affected eye. On close examination of the affected eye, the swirling movement of white thread like worm swimming continuously in aqueous humor of anterior chamber of the eye. It was clearly visible (Figure 1) and diagnosed as Setaria spp. based on location in the anterior chamber of the eye in aberrant host. Microscopic examination of blood smear was positive for microfilaria.

\section{Preoperative Treatment}

Three days before the surgery, the topical antibiotic therapy was changed from $1 \%$ chloramphenicol to tobramycin, twice daily. Concentrate feeding was withheld for 24 hours, whereas water was withheld for 12 hours before surgery. The oral ivermectin was administered before surgery. The blood sample was collected for hematological and biochemical parameters analysis which revealed normal physiological picture except increase in eosinophils, which is shown in table 1 and 2 respectively. The physical examination (auscultation of lung and heart, respiratory rate, pulse rate and rectal temperature) revealed normal physiological condition.

\section{Restraining and Anaesthesia}

The horse was restrained by side line method and positioned in right lateral recumbency on soft bedding. The horse was heavily sedated with intravenous xylazine hydrochloride at the dose of $1.1 \mathrm{mg} / \mathrm{kg}$ body weight. $0.5 \%$ proparacaine hydrochloride was topically installed on the left eye to fix the eyeball. General anaesthesia was induced with intravenous ketamine hydrochloride at the dose of $2.2 \mathrm{mg} / \mathrm{kg}$ body weight and maintained by gaseous anaesthetic isoflurane, delivered in oxygen (Figure 2).

\section{Surgical Procedure}

The periocular skin of the left eye was prepared for surgery with aseptic technique. Conjunctiva and corneal surface were rinsed twice with $1 \%$ povidone iodine solution. The eyeball was held and fixed in a stable position with the hand so as to expose the entire cornea. The surgical site for needling technique was at the 1 O'clock position of the cornea, approximately $1 \mathrm{~mm}$ from the limbus bordering the clear cornea. To aspirate the parasite, a 16 gauge needle was slowly inserted into the anterior chamber of eye through the limbus at 1 O'clock position connected to a $10 \mathrm{ml}$ syringe (Figure 3). The parasite was clearly visualized due to less cloudiness of cornea and slow movement of parasite (Figure 1). Due to the aqueous humor pressure, the eye worm escaped through the needle hub or appeared at the puncture site facilitating its removal. The level of the needle was maneuvered and as the migrating parasite trespasses the level of needle, it was immediately aspirated (Figure 4) and finally 
retrieved. After the removal of the parasite, the operated eye was thoroughly flushed with normal saline. The worm was then collected and immediately submerged into $70 \%$ alcohol solution for further morphological examination. Aqueous leakage was minimal as the needle puncture hole was very small. The puncture site was left as such without suturing in the insertion site. The anterior chamber was reinflated with balanced salt solution and small amount of air. Immediately after the operation, ceftriaxone at the dose of $10 \mathrm{mg} / \mathrm{kg}$ body weight, dexamethasone at the dose of $2 \mathrm{mg} / \mathrm{kg}$ body weight and chlorpheniramine meleate at the dose of 0.5 $\mathrm{mg} / \mathrm{kg}$ body weight were administered intramuscularly.

\section{Postoperative Treatment}

The patient was monitored with vital sign monitor (Figure 5) from induction to recovery. Postoperatively, it was advised to the owner to cover the eye with a piece of clean cloth to avoid direct sunlight falling on to the affected eye. Topical antibiotic, tobramycin 4 drops thrice daily was prescribed for 2 weeks. Dexamethasone eye drops were also prescribed to manage corneal opacity. It was advised to the owner for further hematological examination by postoperative day 10 .

\section{Results}

The horse had the history of continuous lacrimation and movement of worm in the affected eye for 7 days. The clinical examination of the eye revealed mild degree of corneal opacity, conjunctivitis and impaired vision. The swirling movement of the white thread like worm in the aqueous humor was noticed. Heart rate, respiratory rate and rectal temperature were within normal physiological limits. None of the anthelmentics were administered to the horse. There was very less aqueous leakage and no complaint of eyeball shrinkage in operated eye. $1^{\text {st }}$ day after surgery mild reddening and congestion in the cornea found (Figure 6) which was diminished later. Gradual reduction in lacrimation, conjunctivitis and corneal opacity was noticed on day 5 of post-operative treatment (Figure 7). By post-operative day 14, the corneal opacity was subsided gradually and the cornea regained transparency and vision without any complication. There found no microfilaria in hematological examination. The retrieved worm was identified as Setaria spp. based on the morphology (Figure 8) and location in an aberrant host. It was approximately $3.6 \mathrm{~cm}$ long with a straight tail. Microscopic examination of the worm revealed several anterior (Figure 9) and posterior (Figure 10) papillae. The number of papillae could not be counted from this specimen. Spicules were also noticed at the posterior end of the specimen.

Table 1. Hematological parameters analysis.

\begin{tabular}{lll}
\hline Name of The Test & Result & Reference Value \\
\hline Haemoglobin (mg/dl) & 16.2 & $11-19$ \\
Total count of RBC (million/cumm) & 8.29 & $6-10$ \\
Total count of WBC (Thousand/cumm) & 6.55 & $6-12$ \\
PCV (\%) & 40 & $32-53$ \\
Differential count of WBC & & \\
Lymphocytes (\%) & 24 & $15-50$ \\
Neutrophils (\%) & 48 & $35-75$ \\
Eosinophils (\%) & 20 & $2-12$ \\
Monocytes (\%) & 7 & $2-10$ \\
Basophils (\%) & 1 & $0-3$ \\
\hline
\end{tabular}

Table 2. Biochemical parameters analysis.

\begin{tabular}{lll}
\hline Name of The Test & Result & Reference Value \\
\hline Total Protein $(\mathrm{g} / \mathrm{dl})$ & 5.45 & $5.2-7.9$ \\
Glucose $(\mathrm{mg} / \mathrm{dl})$ & 65.8 & $70-115$ \\
Blood Urea Nitrogen $(\mathrm{mg} / \mathrm{dl})$ & 14.7 & $10-24$ \\
Creatinine $(\mathrm{mg} / \mathrm{dl})$ & 1.34 & $1.2-1.9$ \\
Aspertate Amino Transferase $(\mathrm{u} / \mathrm{l})$ & 240 & $226-336$ \\
Alanine Amino Transferase $(\mathrm{u} / \mathrm{l})$ & 9.5 & $3-23$ \\
\hline
\end{tabular}




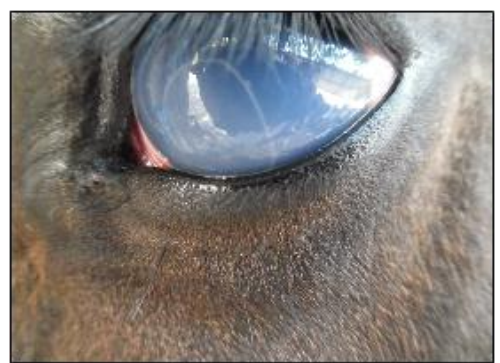

Figure 1. Live worm in the eye before surgery

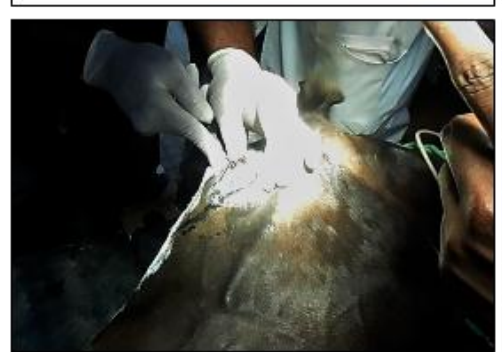

Figure 3. Inserting of $16 \mathrm{G}$ needle at 1 O'clock position through the limbus

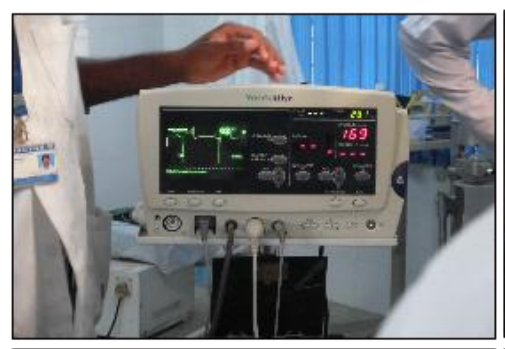

Figure 5. Vital sign monitoring during surgery

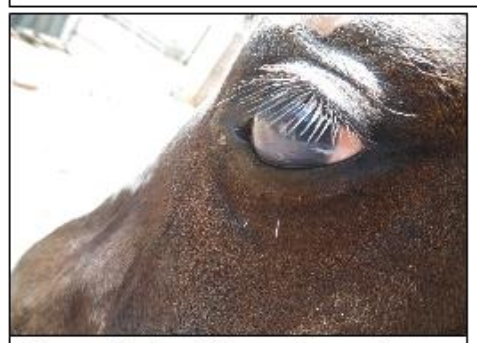

Figure 7. Condition of corneal opacity by post-operative day 5

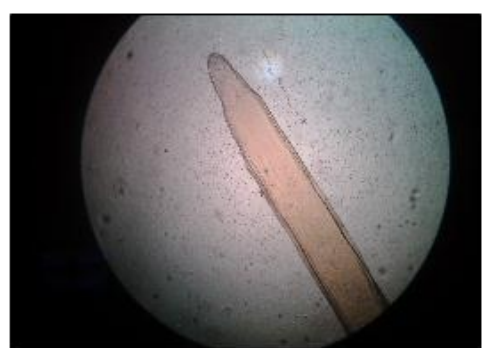

Figure 9. Papilla at anterior end of the parasite

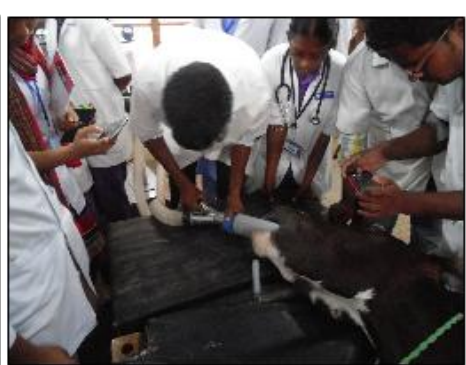

Figure 2. Anesthetized animal for surgery

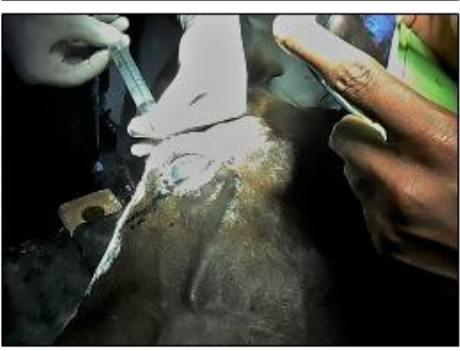

Figure 4. Needle aspiration for retrieval of the worm

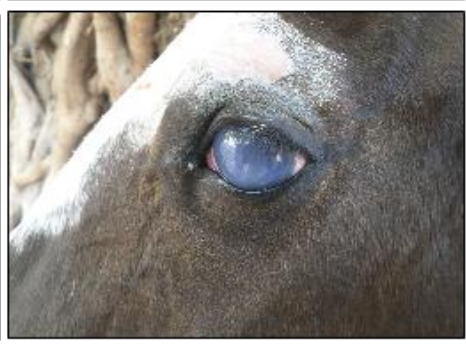

Figure 6. Condition of corneal opacity by post-operative day 1

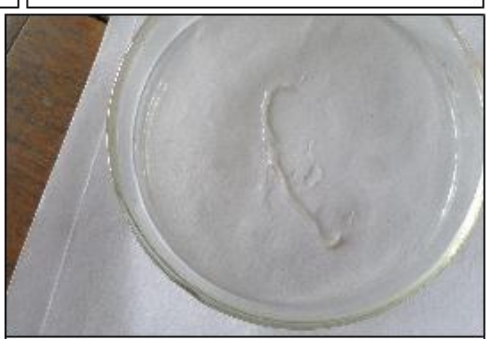

Figure 8. Gross morphology of retrieved parasite

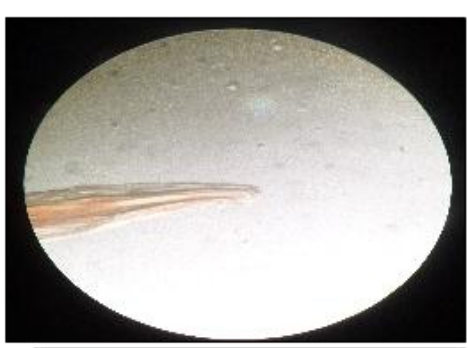

Figure 10. Spicule at the posterior end of the parasite and straight tail 


\section{Discussion}

The adult Setaria spp., usually found in the peritoneal cavity of cattle and normally considered as harmless to the host (Mritunjay et al., 2011). But the heterotrophic parasitisim of the worm in the present study caused detrimental changes to the cornea leading to corneal opacity in horse (Gangwar et al., 2008; Mritunjay et al., 2011). According to Nair et al. (1993); Shin et al. (2002) ectopic parasitism of Setaria spp. has been found in eye and in corpus luteum of the ovary of cattle. Species of the genus Setaria commonly found in the peritoneal cavity, sometimes they may undergo erratic migration in animal (Nair et al., 1993). On a very rare case, the adult worms may migrate erratically towards eye and cause corneal opacity (Shin et al., 2002). The mode of heterotrophic parasitism occurred in the present study remains unknown, it can be hypothesized either to the erratic migratory behavior of parasite or may have occurred when infected mosquitoes fed around eyes and deposited the larvae into the affected eye, which might have migrated to the aqueous humor. Several cases has also been reported related to ocular setariasis in horse (Ansari, 2005; Bhatt et al., 2005; Buchoo et al., 2005; yadav et al., 2005; Jaiswal et al., 2006) where they observed clinical signs like initial lacrimation, conjunctivitis, photophobia followed by cloudiness of cornea and ultimately resulting corneal opacity. However, similar clinical signs have also been found in the present case. Corneal edema is found due to dead filarial worm in the anterior chamber with attachment to the endothelium (Basak et al., 2007). Possibly, the dead worm can liberate toxins into the anterior chamber that is lethal to the endothelium and conferring corneal edema. Such type of edema had not been found in the present study as the worm was alive. Muhammad and saquib (2007) had been advocated both medical and surgical treatments for the equine ocular filariasis although the surgical (needle aspiration) technique has been performed in the present study as it was possible to retrieve the worm completely. A variety of information is scientifically available regarding techniques either by aspiration or incision for removal of Setaria spp. from anterior chamber of eye. However, there are some advantages as well as limitations of both surgical procedures that need to be considered. We performed needle aspiration technique because application of 16 gauze needle connected with $10 \mathrm{ml}$ syringe through the limbus into the anterior chamber is simple, easy and quick method without complication (Singh et al., 1976). There are reports on the successful retrieval of intraocular parasites by aspiration from the horse eye (Gangwar et al., 2008) and cattle eye (Shin et al., 2002) using a 16 gauge needle connected to a $10 \mathrm{ml}$ syringe and an 18 gauge needle connected to a $10 \mathrm{ml}$ syringe, respectively. In this study, 16-gauge needle was used to puncture the cornea and to aspirate the worm. The selection of the aspiration device with a 16 gauge needle may play a role in the removal of the worm because of its adequate diameter and to preclude the chance of iris relapse during aspiration (Tuntivanich et al., 2011). In a study, Tuntivanich et al. (2011) used an 18 gauge needle to remove the worm but the parasite could not be removed and an additional incision on the cornea was required. However, no additional incision was required in the present study to remove the worm. Singh et al. (1976) said not to give the stab incision because of a likelihood of shrinkage of the eyeball as a result of aqueous humor effusion. There is a possibility that several factors, such as location, width, method, and closure of corneal incision or a combination, may play a part in the effusion of aqueous humor from the eyeball. To minimize a possibility of aqueous leakage, the stab incision should made in a closed valve manner (Kalpravidth et al., 1992) using a $3 \mathrm{~mm}$ slit, ophthalmic, crescent, angled knife and the corneal wound should be closed with a fine suture material which is laborious and difficult to do in comparison to needle aspiration technique. Administration of topical antibiotic is recommended because bacterial keratitis is common in horses. As for prophylaxis, chloramphenicol was initially used in this horse, which was later changed into tobramycin. Staphylococcus spp. and Streptococcus spp. are the most common gram positive isolates, whereas Pseudomonas spp. is the most common gramnegative organism isolated from equine bacterial keratitis (Keller et al., 2005). Chloramphenicol is ineffective against these organisms (Moore et al., 1994) whereas tobramycin is highly effective against gram-negative bacteria (Keller et al., 2005). According to these two reports, awareness of chloramphenicol resistance and a concern of Pseudomonas spp. in tropical countries, such as India had led to a preference of tobramycin over chloramphenicol. A combination of antibiotics and corticosteroids is administered postoperatively to reduce intraocular inflammation and corneal opacity. Ivermectin was administered preoperatively because no anthelmentics were given to the present horse. The incidence of the intraocular filarial nematode may be minimized by treatment with ivermectin at a dose of 200-300 micrograms/kg given orally (Mohammad and Saquib, 2007; Laaksonen et al., 2008). Recovery of the corneal opacity may vary after surgery. In the present study, it was observed that the corneal transparency was subsided in 14 days postoperatively which is not agreement with the previous study where there was found complete corneal transparency in 18-21 days (Buchoo et al., 2005; and Jaiswal et al., 2006). It was occurred due to mild degree of opacity in the present study. The retrieved worm was long slender approximately $3.6 \mathrm{~cm}$ in length and possessed both anterior and posterior papillae with spicules only at posterior end which are the morphology of Setaria spp. (Soulsby, 1982). 


\section{Conclusions}

Removal of ocular parasite through the needling technique under general anaesthesia is costly. But it is more preferable in horses particularly in aggressive one. Because the Setaria spp. present into the anterior chamber of eye can successfully retrieve by using this technique without serious complications. After surgery, vision was found clear, corneal opacity was gradually reduced and the horse performed well on a daily basis. This technique can also adopt in our country for the correction of ocular setariasis in animals and the recovery of the corneal opacity can be studied.

\section{Acknowledgements}

The authors gratefully admits the help of Dr. S. Senthilkumar, Assistant Professor and Dr. K. Jayakumar, Assistant Professor, Department of Veterinary Surgery and Radiology, VCRI, Namakkal for their cordial supervision, scholastic guidance, and valuable suggestion during study Period.

\section{Conflict of interest}

None to declare

\section{References}

Ansari MM and BA Buchoo, 2005. Surgical technique for removal of intraocular parasite in horse. Intas Polivet., 6: 256.

Basak SK, TK Hazra and D Bhattacharya, 2007. Persistent corneal edema secondary to presumed dead filarial worm in the anterior chamber. Indian J. Ophthalmol., 55: 67-69.

Bhatt P, K Suresh, S Kumar and MA Khan, 2004. Treatment of ocular Setariasis in equine. Centaur., 21: 68-69.

Buchoo BA, RAS Pandit, JD Parrah and MM Darzl, 2005. Surgical management and prevalence of ocular filariasis in equines. Indian Vet. J., 82: 81-82.

Gangwar AK, D Sangeetha, HN Singh and A Singh, 2008. Ocular filariasis in equines. Indian Vet. J., 85: 547548.

Jaiswal S, SV Singh, B Singh and HN Singh, 2006. Ocular setariasis in a horse. Intas Polivet., 7: 67-68.

Kalpravidh M, A Bramasa and C Kalpravidth, 1992. Surgical removals of intraocular parasites from the anterior chambers of the horse eyes. Thailand J. Vet. Med., 22: 13-20.

Keller RL and DV Hendrix, 2005. Bacterial isolates and antimicrobial susceptibilities in equine bacterial ulcerative keratitis (1993-2004). Equine Vet. J., 37: 207-211.

Laaksonen S, A Oksanen, T Orro, H Norberg, M Nieminen and A Sukura, 2008. Efficacy of different treatment regiments against setariasis (Setaria tundra, Nematoda: Filarioidea) and associated peritonitis in reindeer. Acta. Vet. Scand., 50: 49-57.

Mandal SC and S Ray, 1994. Note on uncommon occurrence of Setaria labiatopapillosa. Indian Vet. J., 71: 726.

Moore CP, BK Collin and WH Fale, 1995. Antibacterial susceptibility patterns for microbial isolates associated with infectious keratitis in horses: 63 cases (1986-1994). J. Am. Vet. Med. Assoc., 207: 928-33.

Mritunjay K, SW Monsang, AM Pawde, SK Singh, DN Madhu and MMS Zama, 2011. Post-surgical healing effect of placentrex in equine (Equus cabalus) ocular setariasis: A review of 22 cases. Indian Field Vet. J., 6: 71-73

Muhammad G and M Saqib, 2007. Successful treatment of ocular equine microfilariasis (Setaria spp.) with ivermectin. Vet. Rec., 160: 25-6.

Nair KP, KM Pillai and V George, 1993. Setaria digitata as ectopic parasite in the cystic corpous luteum of a cow. J. Vet. Anim. Sci., 24: 92-93.

Shin S, K Cho and S Wee, 2002. Ocular infection of cattle with Setaria digitata. J. Vet. Med. Sci., 64: 7-10.

Singh H, PC Chaudhuri and A Kumar, 1976. Paracentesis oculi: a preferred technique for removal of intraocular parasites in horses. Indian Vet. J., 53: 467-468.

Soulsby EJL, 1982. Helminthis, Arthropods and Protozoa of domesticated animals, $7^{\text {th }}$ ed. Baillire, Tindall, London, pp. 316-319.

Sreedavi C, K Sudhakar, PR Murthy and V Prasad, 2002. Clinical microfilariasis in a horse: A case report. Indian Vet. J., 79: 487-488.

Townsend WM, 2013. Food and fiber-producing animal ophthalmology. In: Essentials of veterinary ophthalmology, Gelatt, K.N. (editors). 2nd ed., Wiley-Blackwell, pp. 532.

Tuntivanich N, T Sonthaya, and T Pranee, 2011. Success of Anterior Chamber Paracentesis as a treatment for Ocular Setariasis in Equine Eye: Case Report. Equine Vet. Sci. J., 31: 8-12. 
Varma AK., BN Sahai, SP Singh, P Lakra and VK Shrivastava, 1971. On Setaria digitata, its specific characters, incidence and development in Aedes vittatus and Armigeres obturbans in India with a note on its ectopic occurrence. Parasitenk., 36: 62-72.

Yadav GU, VD Aher, AU Bhikane, YV Raote, GP Bharkad and BN Ambore. 2005. Ocular filariasis in horses and its surgical treatment. Intas Polivet., 6: 262-263. 